\title{
Assessment of a Mitotoxic and Oxidant-Based Strategy in Carcinoid Cancers
}

\author{
Shadi Zahedi", Tetyana Zhelay", and David R. Giovannucci ${ }^{*}$ \\ *Dept. of Neurosciences, College of Medicine, University of Toledo, Toledo, OH, 43614
}

Studies by others showed that a combination of vitamin $\mathrm{C}$ and a quinone compound such as vitamin $\mathrm{K}_{3}\left(\mathrm{Vit} \mathrm{C} / \mathrm{K}_{3}\right.$ ) generates redox-cycling that leads to overproduction of reactive oxygen species (ROSs). Because many cancer cells have been shown to concentrate these compounds compared to non-transformed cells, $\mathrm{V}$ it $\mathrm{C} / \mathrm{K}_{3}$ treatment has been suggested as a cytotoxic therapy for some cancers $[1,2]$. However, the effectiveness of $\mathrm{Vit} \mathrm{C} / \mathrm{K}_{3}$ has not yet been investigated in carcinoid tumors, which are rare aggressive, slow-growing gastrointestinal malignancies of a neuroendocrine phenotype. To date, numerous therapeutic and diagnostic challenges remain for this type of cancer.

To address whether carcinoid cancer cells might be susceptible to such treatments, we treated human bronchial and pancreatic carcinoid cell lines, $\mathrm{H} 727$ and BON, as well as human breast cancer cell lines, MDA-MB231 and MCF7 with $\mathrm{Vit} \mathrm{C} / \mathrm{K}_{3}$ mixture for 24 hours. Cell viability was subsequently determined using the CyQuant Cell Proliferation Assay and data indicated a significant reduction in cell numbers after treatment in both breast and carcinoid cell lines.

To further investigate this observation, we measured evoked increases in hydrogen peroxide $\left(\mathrm{H}_{2} \mathrm{O}_{2}\right)$ and superoxide anion $\left(\mathrm{O}_{2}^{-}\right)$, the two major ROSs, using ROS-sensitive fluorescent dyes. $\mathrm{H}_{2} \mathrm{O}_{2}$ levels were significantly enhanced in all cell lines. However, the level of superoxide anion appeared to be significantly increased in breast cancer cell lines and only in the H727 carcinoid cell line, and the increases in superoxide levels correlated with increased cell death.

Since mitochondria are a source as well as a target of ROS, we investigated mitochondrial morphology, function, and $\mathrm{Ca}^{2+}$ dynamics prior to and following $\mathrm{Vit} \mathrm{C} / \mathrm{K}_{3}$ treatment.

Cancer cell mitochondria showed rapid and dynamic changes in morphology following treatment as determined by confocal analysis. Mitochondrial membrane potential (determined by JC-1 method) was significantly reduced in all cell lines following treatment. Previous work by our group and others has shown that mitochondria are important regulators of voltage-operated and non-voltage-operated $\mathrm{Ca}^{2+}$ entry $[3,4]$. Therefore, the effect of $\mathrm{Vit} \mathrm{C} / \mathrm{K}_{3}$ treatment on the rates and the amplitudes of $\mathrm{Ca}^{2+}$ influx following activation of $\mathrm{Ca}^{2+}$ entry was determined using $\mathrm{Ca}^{2+}$ imaging techniques. Treatment with $\mathrm{V}$ it $\mathrm{C} / \mathrm{K}_{3}$ significantly reduced $\mathrm{Ca}^{2+}$ entry in all cell lines tested and diminished the frequency and maintenance of hormone-evoked $\mathrm{Ca}^{2+}$ oscillations in carcinoid cell lines.

Overall, our data indicate that Vit $\mathrm{C} / \mathrm{K}_{3}$ treatment is cytotoxic to breast and carcinoid cancer cell lines and that the mechanism of toxicity appears to be associated with a direct oxidant challenge to mitochondria. Further studies will determine if this treatment strategy alone or in combination with other modalities can help combat carcinoid cancer effectively. 
References

[1] Verrax, J., et al., In situ modulation of oxidative stress: a novel and efficient strategy to kill cancer cells. Curr Med Chem, 2009. 16(15): p. 1821-30.

[2] Takemura, Y., et al., High dose of ascorbic acid induces cell death in mesothelioma cells. Biochem Biophys Res Commun. 394(2): p. 249-53.

[3] Mignen, O., et al., Carboxyamidotriazole-induced inhibition of mitochondrial calcium import blocks capacitative calcium entry and cell proliferation in HEK-293 cells. J Cell Sci, 2005. 118(Pt 23): p. 5615-23.

[4] Giovannucci, D.R., M.D. Hlubek, and E.L. Stuenkel, Mitochondria regulate the Ca(2+)exocytosis relationship of bovine adrenal chromaffin cells. J Neurosci, 1999. 19(21): p. 9261-70. 